\title{
Association of ATP-Binding Cassette Transporter A1 Gene Polymorphisms in Type 2 Diabetes Mellitus among Malaysians
}

\author{
Polin Haghvirdizadeh, ${ }^{1}$ Vasudevan Ramachandran, ${ }^{2}$ Ali Etemad, ${ }^{1}$ Farzad Heidari, ${ }^{1}$ \\ Nooshin Ghodsian, ${ }^{1}$ Norzian Bin Ismail, ${ }^{3}$ and Patimah Ismail ${ }^{1}$ \\ ${ }^{1}$ Genetic Research Group, Department of Biomedical Science, Faculty of Medicine and Health Sciences, Universiti Putra Malaysia, \\ 43400 Serdang, Selangor, Malaysia \\ ${ }^{2}$ Institute of Gerontology, Universiti Putra Malaysia, 43400 Serdang, Selangor, Malaysia \\ ${ }^{3}$ Department of Medicine, Faculty of Medicine and Health Sciences, Universiti Putra Malaysia, 43400 Serdang, Selangor, Malaysia
}

Correspondence should be addressed to Vasudevan Ramachandran; vasuphd@gmail.com and

Patimah Ismail; patimahismail@gmail.com

Received 13 November 2014; Accepted 2 January 2015

Academic Editor: Aziz Ghahary

Copyright @ 2015 Polin Haghvirdizadeh et al. This is an open access article distributed under the Creative Commons Attribution License, which permits unrestricted use, distribution, and reproduction in any medium, provided the original work is properly cited.

\begin{abstract}
Background. Type 2 diabetes mellitus (T2DM) is a complex polygenic disorder characterized by impaired insulin resistance, insulin secretion, and dysregulation of lipid and protein metabolism with environmental and genetic factors. ATP-binding cassette transporter $\mathrm{Al}$ (ABCA1) gene polymorphisms are reported as the one of the genetic risk factors for T2DM in various populations with conflicting results. This study was conducted based on PCR-HRM to determine the frequency of ABCA1 gene by rs 2230806 (R219K), rs1800977 (C69T), and rs9282541 (R230C) polymorphisms Malaysian subjects. Methods. A total of 164 T2DM and 165 controls were recruited and their genotypes for ABCA1 gene polymorphisms were determined based on the real time high resolution melting analysis. Results. There was a significant difference between the subjects in terms of age, BMI, FPG, HbA1c, HDL, LDL, and TG $(P<0.05)$. There was a significant association between HOM of R219K $(P=0.005)$, among Malaysian subjects; moreover, allele frequency revealed the significant difference in A allele of R219K $(P=0.003)$. But, there was no significant difference in genotypic and allelic frequencies of $\mathrm{C} 69 \mathrm{~T}$ and R230C polymorphism. Conclusion. R219K polymorphism of ABCA1 gene can be considered as a genetic risk factor for T2DM subjects among Malaysians.
\end{abstract}

\section{Background}

Diabetes is one of the four main noncommunicable diseases (NCDs) identified by the World Health Organization (WHO), besides the cardiovascular disease, cancer, and chronic respiratory diseases [1]. Asia has become the major site of a quickly emerging diabetes epidemic. In Malaysia, the latest National Health and Morbidity Survey in 2008 already demonstrated an increase of prevalence of diabetes mellitus from $8.3 \%$ to $11.6 \%$ [2]. Type 2 diabetes mellitus (T2DM) is a complex polygenic disorder characterized by impaired insulin resistance, insulin secretion, and dysregulation of lipid and protein metabolism with environmental and genetic factors [3]. The complications of diabetes have become the leading causes of mortality and morbidity worldwide [4]. The prevalence of T2DM is swiftly increasing to 300 million people by the year 2025 [5]. Although several association studies suggested various candidate genes for T2DM in different populations, the role of genetic polymorphisms involved in the development of diabetes still remains unclear [6]. The ATP-binding cassette transporter A1 (ABCA1) gene located on the chromosome 9 region q31.1 involved in the transport of cholesterol and phospholipids from cells to lipid-poor apolipoproteins [7]. Besides, some investigations demonstrated that familial hypoalphalipoproteinemia can be caused by heterozygosity and Tangier disease can be caused by homozygous mutations. Moreover, genetic and molecular biology researchers have suggested that low plasma HDLcholesterol can reflect an impaired ABCAl pathway that can also elevate the accumulation of cholesterol in tissue macrophages [8]. 
Analyzing the genetic and allelic frequency of polymorphisms among case and control studies can provide supporting evidence to show their role in individual subjects. The genetic polymorphisms of ABCAl gene provide a basis for studying the association between genetic variants and the development of T2DM in this ethnic group. Based on literature review, most of the studies were done on 3 common polymorphisms, so this study was conducted to determine genetic polymorphism of the rs2230806 (R219K), C69T (rs1800977), and R230C (rs9282541) among T2DM subjects.

\section{Results}

A total of 329 subjects were approached in this study that were divided into 2 groups: 165 controls and 164 T2DM subjects. In this study, the association of anthropometric and social demographic factors and major risk factors in T2DM with ABCA1 polymorphism among Malaysian subjects was investigated.

The means of age, BMI, systolic blood pressure (SBP), FPG, HbAlc, HDL, and triglyceride (TG) among T2DM patients were higher than control group; moreover, diastolic blood pressure (DBP), low density lipoprotein (LDL), and cholesterol in control subjects were higher than T2DM patients. The control samples had mean age $54.97 \pm 11.79$ and patients had mean age $62.14 \pm 9.56$. Mean BMI were almost equal: $27.08 \pm 6.26$ in control and $28.60 \pm 13.98$ in case samples. Mean of SBP among controls was $137.89 \pm 20.22$ and among case subjects was $141.83 \pm 24.41$ and mean of DBP was $79.54 \pm 10.52$ between control groups and $78.32 \pm 12.14$ between case subjects. Mean of FPG was higher among case subjects $(8.66 \pm 3.50)$ and in control samples was $5.45 \pm 1.31$. Mean of HbAlc among patients $(7.90 \pm 2.08)$ is higher than controls $(5.94 \pm 0.65)$. The means of cholesterol, LDL, HDL, and TG between case and control subjects are almost equal. Maximum age between case and control subjects is 85 years and minimum age in control is 26 years and in case is 41 years. Based on this table the significant difference was detected in the level of age $(P$ value $=0.000)$, FPG $(P$ value $=0.000)$, HbAlc $(P$ value $=0.000)$, LDL $(P$ value $=0.010)$, and TG $(P$ value $=0.000)$ between T2DM and control subjects (Table 1 ).

2.1. R219K. Analysis of R219K polymorphism with $73 \mathrm{bp}$ PCR product with mutation $(\mathrm{G} \rightarrow \mathrm{A}$ ) was amplified by PCR-HRM. Figure 1 showed three different graphs that can detect three different genotypes of R219K polymorphism. The genotypic and allelic frequencies of R219K were shown in Table 2 that demonstrated the significant difference genotypes of this polymorphism. The clinical and biochemical characteristics were demonstrated in Table 3 for this polymorphism. Based on this table the $P$ value showed FPG $(0.036)$ was significantly higher in WT in both groups. There was significantly higher difference in the mean of HbAlc of WT for both subjects $(P=0.001)$.

2.2. C69T. Analysis of C69T polymorphism with $85 \mathrm{bp}$ PCR product length with mutation $(\mathrm{C} \rightarrow \mathrm{T})$ was amplified by PCR-HRM. Figure 2 showed three different graphs that can detect three different genotypes of C69T polymorphism. The
TABLE 1: Clinical and biochemical characteristics between T2DM and control subjects.

\begin{tabular}{lccc}
\hline Parameters & $\begin{array}{c}\text { T2DM } \\
(n=164)\end{array}$ & $\begin{array}{c}\text { Controls } \\
(n=165)\end{array}$ & $P$ value \\
\hline Age (years) & $62.14 \pm 9.56$ & $54.97 \pm 11.79$ & $0.000^{*}$ \\
BMI $\left(\mathrm{Kg} / \mathrm{m}^{2}\right)$ & $27.86 \pm 5.14$ & $27.08 \pm 6.26$ & 0.22 \\
WHR & $0.96 \pm 0.15$ & $0.95 \pm 0.56$ & 0.876 \\
SBP $(\mathrm{mm} \mathrm{Hg})$ & $141.83 \pm 24.41$ & $137.89 \pm 20.22$ & 0.117 \\
DBP $(\mathrm{mm} \mathrm{Hg})$ & $78.30 \pm 12.14$ & $79.55 \pm 10.52$ & 0.325 \\
FPG $(\mathrm{mmol} / \mathrm{L})$ & $8.66 \pm 3.50$ & $5.45 \pm 1.31$ & $0.000^{*}$ \\
HbAlc $(\mathrm{mmol} / \mathrm{mol})$ & $7.98 \pm 2.18$ & $5.94 \pm 0.65$ & $0.000^{*}$ \\
LDL $(\mathrm{mmol} / \mathrm{L})$ & $2.35 \pm 0.90$ & $2.62 \pm 0.95$ & $0.010^{*}$ \\
HDL $(\mathrm{mmol} / \mathrm{L})$ & $1.26 \pm 0.48$ & $1.21 \pm 0.43$ & 0.303 \\
TG $(\mathrm{mmol} / \mathrm{L})$ & $1.76 \pm 1.20$ & $1.27 \pm 0.76$ & $0.000^{*}$ \\
Cholesterol $(\mathrm{mmol} / \mathrm{L})$ & $4.38 \pm 1.14$ & $4.43 \pm 1.17$ & 0.675 \\
\hline
\end{tabular}

Values shown are the mean $\pm \mathrm{SD}, P<0.05$.

*Significant parameters.

genotypic and allelic frequencies of C69T were shown in Table 2 that did not demonstrate any differences for this polymorphism. The clinical and biochemical characteristics of this polymorphism were demonstrated in Table 4.

2.3. R230C. Analysis of R230C polymorphism with $87 \mathrm{bp}$ PCR product length with mutation $(\mathrm{C} \rightarrow \mathrm{T})$ was amplified by PCR-HRM. Figure 3 showed three different graphs that can detect three different genotypes of R230C polymorphism. The genotypic and allelic frequencies of R230C were shown in Table 2 that did not demonstrate any differences for this polymorphism. The clinical and biochemical characteristics of this polymorphism were demonstrated in Table 5.

\section{Discussion}

As revealed in some investigations, the worldwide prevalence of diabetes has gone up and this represents the importance of the study on diabetes; moreover, in Malaysia, the latest National Health and Morbidity Survey in 2008 has already demonstrated an increase in the prevalence of diabetes mellitus from $8.3 \%$ to $11.6 \%$ [19]. The proportion of Malays was higher in both T2DM and control subjects in this study (50.6\% and $50.3 \%$, resp.) in comparison with Indians and Chinese $(29.9 \%$ and $30.3 \%$, resp., for Indians and $19.5 \%$ and $19.4 \%$, resp., for Chinese). Moreover, the proportion of males was higher in T2DM and control subjects (62.8\% and 52.7\%, resp.) in comparison with females (37.2\% and $47.3 \%$, resp.). The significant difference in the levels of age $(P=0.000)$, FPG $(P=0.000)$, LDL $(P=0.010)$, and TG $(P=$ 0.000 ) was observed among the subjects. In previous reports a significant difference was detected in the levels of BMI, HDL, LDL, TG, cholesterol, FPG, SBP, and DBP between T2DM and healthy subjects $[8,13]$. Among overweight/obese population demographic and clinical characteristics were evaluated which demonstrated no significant differences in the level of HDL and LDL but statistical differences were detected in the levels of BMI, cholesterol, and TG [16]. In the 


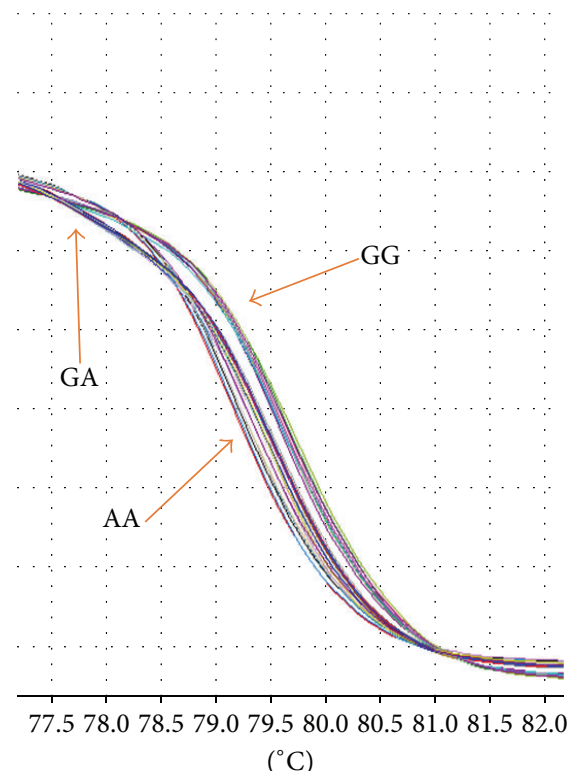

(a)

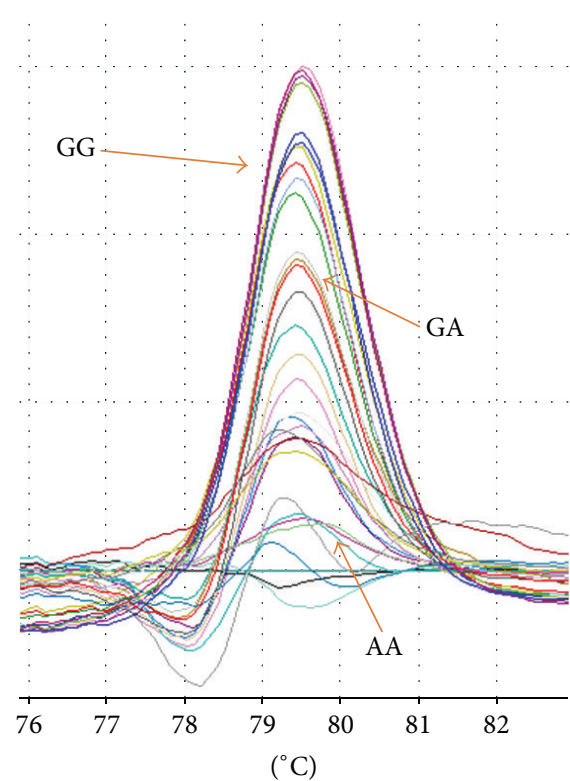

(b)

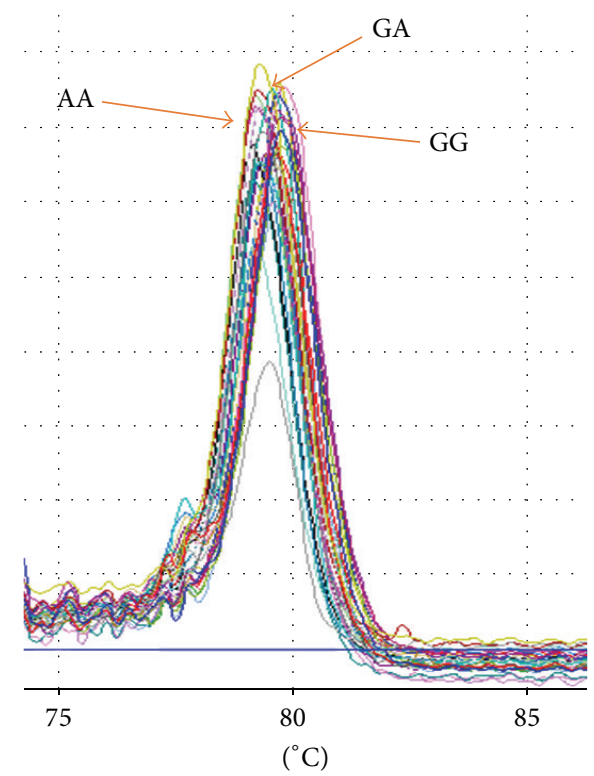

(c)

FIGURE 1: The difference graph of HRM analysis for the genotypes of R219K polymorphism. (a) demonstrated the normalized graph, (b) revealed the difference graph, and (c) was melting graph. In these graphs WT had higher Tm and HOM had lower Tm.

current study, there were no significant differences between genotypes and subjects for R230C and C69T polymorphisms. But, regarding $\mathrm{R} 219 \mathrm{~K}$ there was a significant difference between subjects. Allele frequencies of these polymorphisms revealed no significant difference of R230C but there was a significant difference between alleles of R219K and C69T. Based on genotype and allele frequency of polymorphisms according to gender among subjects, there was no significant difference between genotypes and gender among subjects for any of the polymorphisms but A allele of R219K and C allele of C69T and T allele of R230C had significant differences between genders among subjects.
Genotype and allele frequencies of each polymorphism revealed no significant difference for genotype and allele of C69T and R230C according to race among subjects but R219K had a significant difference in HOM and A allele. R219K was significantly different between metabolic syndrome patients and healthy subjects based on Değer's group research [20].

Opposite to those studies, some researchers showed the significant differences between T2DM and controls: they found TT genotype was significantly higher in controls than in patients, but Alharbi and his colleagues showed the frequency of T allele was higher among patients and Ergen et al. found that $\mathrm{T}$ allele was higher in control groups; moreover 
TABLE 2: Genotypic and allelic frequencies of R219K, C69T, and R230C, respectively, according to subjects.

\begin{tabular}{|c|c|c|c|c|c|}
\hline & & T2DM (\%) & $(95 \% \mathrm{CI})$ & Controls (\%) & $P$ value \\
\hline R219K & GG & $94(57.3 \%)$ & & $56(33.9 \%)$ & \multirow{3}{*}{$0.000^{*}$} \\
\hline \multirow[t]{2}{*}{ Genotypes and alleles } & GA & $55(33.5 \%)$ & & $77(46.6 \%)$ & \\
\hline & AA & $15(9.1 \%)$ & & $32(19.3 \%)$ & \\
\hline \multirow[t]{2}{*}{ Alleles } & G & $243(74 \%)$ & & $189(57.2 \%)$ & \multirow{2}{*}{$0.000^{*}$} \\
\hline & $\mathrm{A}$ & $85(26 \%)$ & & $141(42.8 \%)$ & \\
\hline \multirow{3}{*}{ Post hoc test } & GG versus GA & & $0.07-0.34$ & & $0.001^{*}$ \\
\hline & GG versus AA & & $0.11-0.49$ & & $0.001^{*}$ \\
\hline & GA versus AA & & $-0.09-0.29$ & & 0.467 \\
\hline C69T & $\mathrm{CC}$ & $65(39.6 \%)$ & & $83(50.3 \%)$ & \multirow{3}{*}{ NS } \\
\hline \multirow[t]{3}{*}{ Genotypes and alleles } & $\mathrm{CT}$ & $48(29.2 \%)$ & & $48(29 \%)$ & \\
\hline & $\mathrm{TT}$ & $51(31 \%)$ & & $34(20.6 \%)$ & \\
\hline & $\mathrm{C}$ & $154(54.2 \%)$ & & $190(64.8 \%)$ & \multirow{2}{*}{$0.005^{*}$} \\
\hline Alleles & $\mathrm{T}$ & $150(45.8 \%)$ & & $116(35.2 \%)$ & \\
\hline \multirow{3}{*}{ Post hoc test } & CC versus CT & & $-0.18-0.06$ & & 0.352 \\
\hline & CC versus TT & & $-0.29--0.02$ & & $0.018^{*}$ \\
\hline & CT versus TT & & $-0.24-0.04$ & & 0.179 \\
\hline $\mathrm{R} 230 \mathrm{C}$ & CC & $69(42 \%)$ & & $64(38.7 \%)$ & \multirow{3}{*}{ NS } \\
\hline \multirow[t]{3}{*}{ Genotypes and alleles } & CT & $72(43.6 \%)$ & & $67(40.6 \%)$ & \\
\hline & TT & $32(19.3 \%)$ & & $34(20.6 \%)$ & \\
\hline & $\mathrm{C}$ & $210(63.9 \%)$ & & $195(59 \%)$ & \multirow{2}{*}{0.695} \\
\hline Alleles & $\mathrm{T}$ & $136(36.1 \%)$ & & $135(41 \%)$ & \\
\hline \multirow{3}{*}{ Post hoc test } & CC versus CT & & $0.11-0.12$ & & 0.989 \\
\hline & CC versus TT & & $-0.04-0.27$ & & 0.147 \\
\hline & CT versus TT & & $-0.04-0.26$ & & 0.147 \\
\hline
\end{tabular}

${ }^{*} P<0.05$.

TABLE 3: Clinical and biochemical characteristics among subjects according to genotypes of R219K.

\begin{tabular}{|c|c|c|c|c|c|c|c|}
\hline & \multicolumn{3}{|c|}{$\mathrm{T} 2 \mathrm{DM}(n=164)$} & \multicolumn{3}{|c|}{ Controls $(n=165)$} & \multirow{2}{*}{$P$ value } \\
\hline & GG & GA & AA & GG & GA & AA & \\
\hline Age (years) & $61.94 \pm 9.20$ & $61.40 \pm 9.98$ & $66.06 \pm 9.76$ & $54.94 \pm 11.79$ & $55.38 \pm 12.11$ & $54.06 \pm 10.98$ & 0.583 \\
\hline $\mathrm{BMI}\left(\mathrm{Kg} / \mathrm{m}^{2}\right)$ & $27.68 \pm 5.12$ & $28.32 \pm 5.54$ & $27.29 \pm 3.69$ & $27.53 \pm 8.86$ & $27.17 \pm 4.44$ & $26.08 \pm 4.24$ & 0.767 \\
\hline WHR & $0.95 \pm 0.07$ & $0.97 \pm 0.25$ & $0.96 \pm 0.06$ & $0.88 \pm 0.13$ & $1.02 \pm 0.82$ & $0.91 \pm 0.06$ & 0.791 \\
\hline SBP (mm Hg) & $145.45 \pm 22.85$ & $134.98 \pm 25.86$ & $145.85 \pm 24.12$ & $136.72 \pm 20.59$ & $138.12 \pm 19.44$ & $139.34 \pm 21.93$ & 0.479 \\
\hline DBP (mm Hg) & $78.21 \pm 10.14$ & $78.44 \pm 15.15$ & $78.28 \pm 11.41$ & $79 \pm 11.21$ & $79.36 \pm 10.12$ & $80.96 \pm 10.43$ & 0.481 \\
\hline $\mathrm{FPG}(\mathrm{mmol} / \mathrm{L})$ & $8.76 \pm 3.66$ & $8.65 \pm 3.39$ & $8.11 \pm 3.04$ & $5.62 \pm 1.14$ & $5.35 \pm 1.24$ & $5.42 \pm 1.69$ & $0.036^{*}$ \\
\hline $\mathrm{HbAlc}(\mathrm{mmol} / \mathrm{mol})$ & $8.22 \pm 2.14$ & $7.76 \pm 2.15$ & $7.24 \pm 2.46$ & $5.92 \pm 0.69$ & $5.91 \pm 0.63$ & $6.07 \pm 0.65$ & $0.001^{*}$ \\
\hline $\mathrm{LDL}(\mathrm{mmol} / \mathrm{L})$ & $2.34 \pm 0.92$ & $2.33 \pm 0.87$ & $2.46 \pm 0.94$ & $2.71 \pm 0.95$ & $2.47 \pm 0.91$ & $2.80 \pm 1.03$ & 0.138 \\
\hline $\mathrm{HDL}(\mathrm{mmol} / \mathrm{L})$ & $1.24 \pm 0.40$ & $1.27 \pm 0.54$ & $1.31 \pm 0.69$ & $1.28 \pm 0.44$ & $1.19 \pm 0.46$ & $1.10 \pm 0.29$ & 0.382 \\
\hline $\mathrm{TG}(\mathrm{mmol} / \mathrm{L})$ & $1.85 \pm 1.45$ & $1.58 \pm 0.76$ & $1.90 \pm 0.82$ & $1.26 \pm 0.79$ & $1.29 \pm 0.81$ & $1.25 \pm 0.58$ & 0.139 \\
\hline Cholesterol (mmol/L) & $4.42 \pm 1.19$ & $4.29 \pm 1.08$ & $4.45 \pm 1.11$ & $4.66 \pm 1.16$ & $4.30 \pm 1.21$ & $4.34 \pm 1.04$ & 0.218 \\
\hline
\end{tabular}

${ }^{*} P<0.05$.

these 2 groups did not find any association between C69T and lipid profiles $[8,13]$. R230C polymorphism of ABCA1 gene associated with lower HDL; moreover, C230 allele had a significant association with lower cholesterol and HDL level as well. However, no association was detected between C230 allele and T2DM [15].

Among overweight/obese and control populations there was no significant difference for genotype frequency [16]. Table 6 demonstrated the conflicting results of genetic variants of ABCA1 gene found in different populations compared with the current study.

\section{Conclusion}

The present study has showed a genetic association for R219K, C69T, and R230C polymorphisms of ABCA1 gene among Malaysian T2DM patients compared to control subjects. Replication studies with a larger number of samples on a 


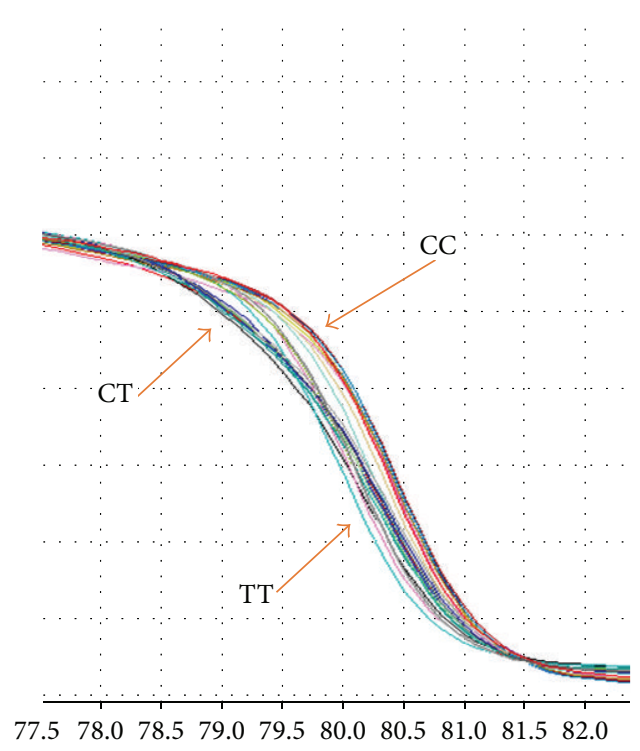

$\left({ }^{\circ} \mathrm{C}\right)$

(a)

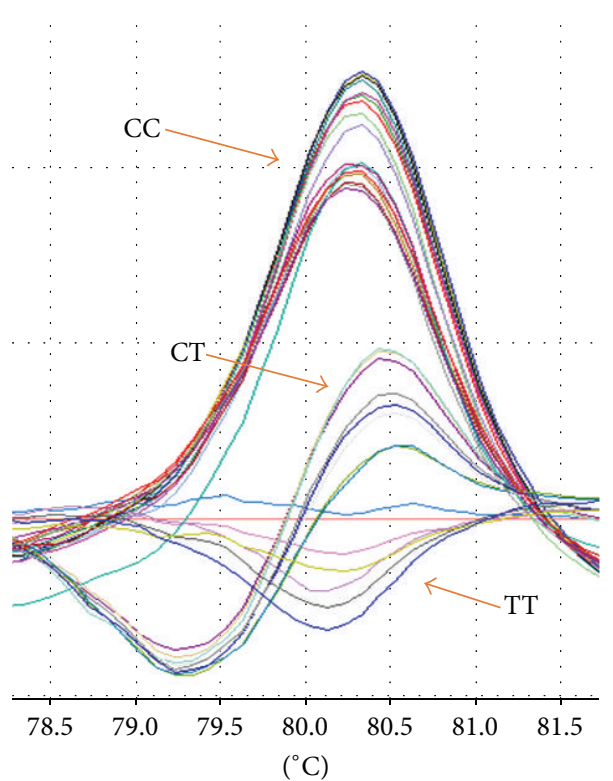

(b)

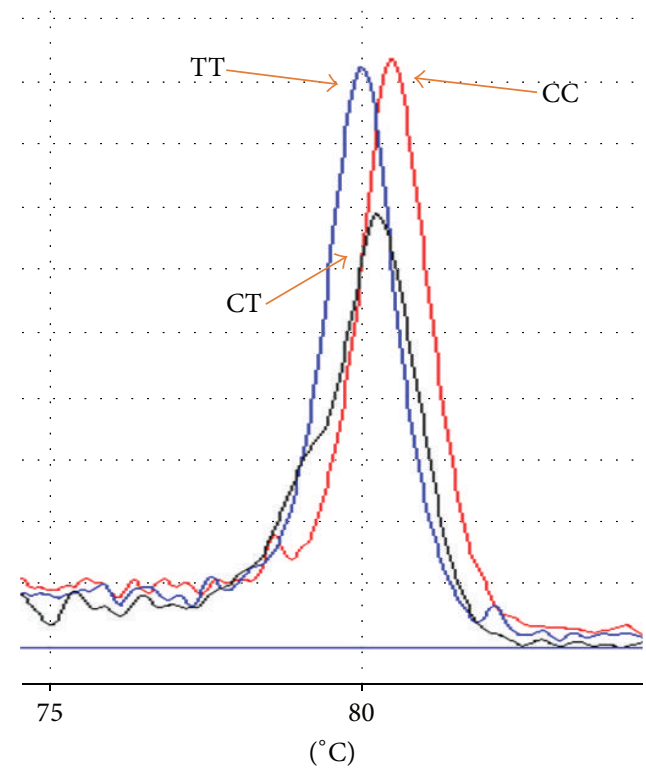

(c)

FIGURE 2: The difference graph of HRM analysis for the genotypes of C69T polymorphism. (a) demonstrated the normalized graph, (b) revealed the difference graph, and (c) was melting graph. In these graphs WT had higher Tm and HOM had lower Tm.

homogenous study population are strongly recommended to confirm the association of ABCAl gene polymorphisms with T2DM.

In the current study, some limitations have been considered. The present study provided only genetic association of ABCA1 gene polymorphisms with T2DM among Malaysian subjects. Apart from the ABCA1 gene polymorphisms, other polymorphisms such as A2589G, G3456C, R1851X, and K776N need to be analyzed to determine the association of the other candidate gene polymorphisms with T2DM and other defects. Table 6 shows the conflicting results of genetic variants found in different populations.

\section{Methods}

5.1. Study Subjects. Ethical approval has been obtained from the Ethical Committee of the National Heart Institute, Malaysia (Reference number IJNEC/05/10 (02)). A total of 164 T2DM subjects were collected from the National Heart Institute, Kuala Lumpur. Subjects were selected as adults $>30$ years of age who were already diagnosed with T2DM and participated in IJN for their T2DM treatment. A questionnaire in both Malay and English languages was obtained to assess the sociodemographic factors. Informed consent was obtained from all the subjects who have participated in this study. 
TABLE 4: Clinical and biochemical characteristics among subjects according to genotypes of C69T.

\begin{tabular}{|c|c|c|c|c|c|c|c|}
\hline & \multicolumn{3}{|c|}{$\mathrm{T} 2 \mathrm{DM}(n=164)$} & \multicolumn{3}{|c|}{ Controls $(n=165)$} & \multirow{2}{*}{$P$ value } \\
\hline & $\mathrm{CC}$ & $\mathrm{CT}$ & TT & $\mathrm{CC}$ & $\mathrm{CT}$ & TT & \\
\hline$\overline{\text { Age (years) }}$ & $61.93 \pm 9.65$ & $62.55 \pm 10.10$ & $62.04 \pm 9.09$ & $55.60 \pm 11.50$ & $54.51 \pm 12.62$ & $54.06 \pm 11.55$ & 0.958 \\
\hline BMI $\left(\mathrm{Kg} / \mathrm{m}^{2}\right)$ & $27.99 \pm 5.07$ & $27.98 \pm 5.53$ & $27.58 \pm 4.94$ & $26.98 \pm 7.32$ & $27.05 \pm 5.22$ & $27.35 \pm 4.72$ & 0.992 \\
\hline WHR & $0.97 \pm 0.23$ & $0.95 \pm 0.65$ & $0.95 \pm 0.07$ & $1.00 \pm 0.87$ & $0.88 \pm 0.05$ & $0.91 \pm 0.07$ & 0.544 \\
\hline SBP (mm Hg) & $142.79 \pm 20.84$ & $143.76 \pm 25.25$ & $138.94 \pm 27.58$ & $137.26 \pm 19.17$ & $137.10 \pm 20.16$ & $140.63 \pm 23.11$ & 0.961 \\
\hline DBP (mm Hg) & $79.20 \pm 14.04$ & $79.69 \pm 11.35$ & $75.96 \pm 10.16$ & $79.13 \pm 10.06$ & $80.43 \pm 11.34$ & $79.33 \pm 10.64$ & 0.256 \\
\hline FPG (mmol/L) & $8.81 \pm 3.27$ & $8.49 \pm 3.64$ & $8.64 \pm 3.72$ & $5.63 \pm 1.57$ & $5.21 \pm 1.03$ & $5.35 \pm 0.79$ & 0.592 \\
\hline $\mathrm{HbAlc}(\mathrm{mmol} / \mathrm{mol})$ & $7.95 \pm 2.29$ & $8.11 \pm 1.93$ & $7.88 \pm 2.32$ & $5.92 \pm 0.68$ & $5.95 \pm 0.55$ & $5.96 \pm 0.72$ & 0.575 \\
\hline $\mathrm{LDL}(\mathrm{mmol} / \mathrm{L})$ & $2.32 \pm 0.91$ & $2.47 \pm 0.97$ & $2.26 \pm 0.81$ & $2.57 \pm 1.00$ & $2.54 \pm 0.93$ & $2.85 \pm 0.86$ & 0.916 \\
\hline $\mathrm{HDL}(\mathrm{mmol} / \mathrm{L})$ & $1.22 \pm 0.49$ & $1.32 \pm 0.46$ & $1.26 \pm 0.50$ & $1.28 \pm 0.43$ & $1.10 \pm 0.39$ & $1.18 \pm 0.45$ & 0.788 \\
\hline $\mathrm{TG}(\mathrm{mmol} / \mathrm{L})$ & $1.93 \pm 1.60$ & $1.56 \pm 0.63$ & $1.73 \pm 0.99$ & $1.23 \pm 0.86$ & $1.21 \pm 0.62$ & $1.48 \pm 0.67$ & 0.291 \\
\hline Cholesterol $(\mathrm{mmol} / \mathrm{L})$ & $4.39 \pm 1.26$ & $4.44 \pm 1.08$ & $4.31 \pm 1.05$ & $4.41 \pm 1.18$ & $4.29 \pm 1.18$ & $4.69 \pm 1.11$ & 0.843 \\
\hline
\end{tabular}

$P$ value $<0.05$, between T2DM and controls.

TABLE 5: Clinical and biochemical characteristics among subjects according to genotypes of R230C.

\begin{tabular}{|c|c|c|c|c|c|c|c|}
\hline & \multicolumn{3}{|c|}{$\mathrm{T} 2 \mathrm{DM}(n=164)$} & \multicolumn{3}{|c|}{ Controls $(n=165)$} & \multirow{2}{*}{$P$ value } \\
\hline & $\mathrm{CC}$ & CT & TT & $\mathrm{CC}$ & $\mathrm{CT}$ & $\mathrm{TT}$ & \\
\hline Age (years) & $62.19 \pm 8.82$ & $62.04 \pm 10.03$ & $62.30 \pm 10.55$ & $56.68 \pm 10.60$ & $52.80 \pm 12.58$ & $56.00 \pm 12.00$ & 0.363 \\
\hline BMI $\left(\mathrm{Kg} / \mathrm{m}^{2}\right)$ & $28.01 \pm 5.33$ & $27.66 \pm 5.27$ & $28.00 \pm 4.26$ & $28.60 \pm 8.05$ & $26.10 \pm 4.53$ & $26.14 \pm 4.72$ & 0.096 \\
\hline WHR & $0.94 \pm 0.05$ & $0.98 \pm 0.22$ & $0.93 \pm 0.05$ & $1.02 \pm 0.94$ & $0.92 \pm 0.06$ & $0.91 \pm 0.08$ & 0.730 \\
\hline $\mathrm{SBP}(\mathrm{mm} \mathrm{Hg})$ & $143.53 \pm 25.25$ & $140.19 \pm 24.75$ & $142.25 \pm 20.98$ & $139.28 \pm 20.19$ & $135.04 \pm 18.38$ & $140.82 \pm 23.40$ & 0.351 \\
\hline DBP (mm Hg) & $78.53 \pm 13.96$ & $77.87 \pm 11.33$ & $79.10 \pm 8.65$ & $79.70 \pm 10.50$ & $78.83 \pm 10.46$ & $80.67 \pm 10.87$ & 0.615 \\
\hline FPG (mmol/L) & $8.66 \pm 3.71$ & $8.88 \pm 3.32$ & $7.93 \pm 3.49$ & $5.42 \pm 0.92$ & $5.50 \pm 1.74$ & $5.42 \pm 0.90$ & 0.193 \\
\hline $\mathrm{HbAlc}(\mathrm{mmol} / \mathrm{mol})$ & $8.10 \pm 2.09$ & $8.02 \pm 2.22$ & $7.41 \pm 2.38$ & $5.83 \pm 0.67$ & $6.01 \pm 0.69$ & $6.00 \pm 0.52$ & 0.192 \\
\hline $\mathrm{LDL}(\mathrm{mmol} / \mathrm{L})$ & $2.58 \pm 1.01$ & $2.18 \pm 0.78$ & $2.13 \pm 0.73$ & $2.59 \pm 0.98$ & $2.72 \pm 0.97$ & $2.48 \pm 0.87$ & 0.241 \\
\hline $\mathrm{HDL}(\mathrm{mmol} / \mathrm{L})$ & $1.33 \pm 0.51$ & $1.23 \pm 0.47$ & $1.12 \pm 0.36$ & $1.18 \pm 0.41$ & $1.23 \pm 0.34$ & $1.20 \pm 0.60$ & 0.494 \\
\hline $\mathrm{TG}(\mathrm{mmol} / \mathrm{L})$ & $1.78 \pm 1.08$ & $1.70 \pm 1.23$ & $1.89 \pm 1.42$ & $1.29 \pm 0.78$ & $1.32 \pm 0.83$ & $1.14 \pm 0.54$ & 0.968 \\
\hline Cholesterol (mmol/L) & $4.69 \pm 1.22$ & $4.16 \pm 1.07$ & $4.08 \pm 0.88$ & $4.40 \pm 1.24$ & $4.56 \pm 1.09$ & $4.25 \pm 1.17$ & 0.119 \\
\hline
\end{tabular}

$P$ value $<0.05$, between T2DM and controls.

TABLE 6: Conflicting results of genetic variants found in different populations.

\begin{tabular}{|c|c|c|c|c|c|}
\hline Gene variants & Diseases & Populations & References & Number of subjects & $P$ value \\
\hline ABCA1 R1587K & CAD & Chinese & Guo et al., 2011 [9] & 222 & NS \\
\hline ABCA1 R219K & $\mathrm{CHD}$ & Turkish & Çoban et al., 2014 [10] & 627 & NS \\
\hline ABCA1 C69T & CAD & Turkish & Ergen et al., 2008 [11] & 127 & NS \\
\hline ABCA1 R219K & $\mathrm{CHD}$ & Spanish & Cenarro et al., 2003 [12] & 216 & $S$ \\
\hline ABCA1 C69T & $\mathrm{T} 2 \mathrm{DM}$ & Saudi Arabian & Alharbi et al., 2013 [13] & 756 & S \\
\hline ABCA1 C69T & $\mathrm{T} 2 \mathrm{DM}$ & Turkish & Ergen et al., 2012 [8] & 157 & S \\
\hline ABCA1 R219K, R1587K, C69T & $\mathrm{T} 2 \mathrm{DM}$ & French & Porchay-Baldérelli et al., 2009 [14] & 482 & NS \\
\hline ABCA1 R230C & CAD & Mexican & Villarreal-Molina et al., 2012 [15] & 2193 & S \\
\hline ABCA1 R219K & Overweight/obese & Thai & Kitjaroentham et al., 2007 [16] & 229 & NS \\
\hline ABCA1 R219K, R1587K, C69T & Ischemic stroke & English & Pasdar et al., 2007 [17] & 887 & $S$ \\
\hline ABCA1 R1219K & $\mathrm{CAD}$ & American & Benton et al., 2007 [18] & 6814 & NS \\
\hline $\mathrm{R} 219 \mathrm{~K}$ & $\mathrm{~T} 2 \mathrm{DM}$ & Malaysian & Current study & 164 & S \\
\hline
\end{tabular}

NS: nonsignificant $(P>0.05)$, S: significant $(P<0.05)$.

A total of 165 control individuals were recruited from the healthy respondents who did not have T2DM at the time of sample collection. The subjects who had been diagnosed with cancer, type 1 diabetes, genetic malformation, and pregnancy are excluded from this study.
5.2. Genomic DNA Extraction. The buccal and blood samples were collected from the respective subjects. The genomic DNA was extracted from blood and buccal samples by using the extraction kits (QIGEN) and used for amplification of the candidate genes and then the extracted genomic DNA was 


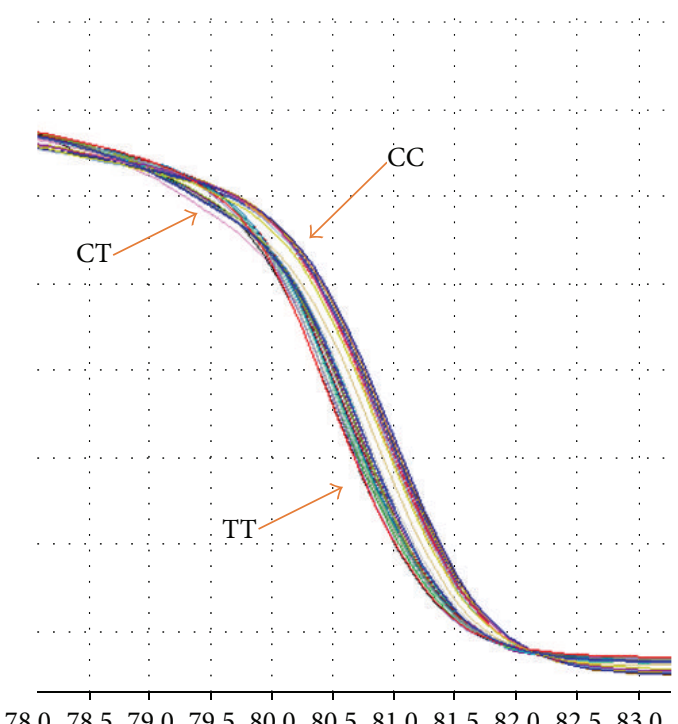

$\left({ }^{\circ} \mathrm{C}\right)$

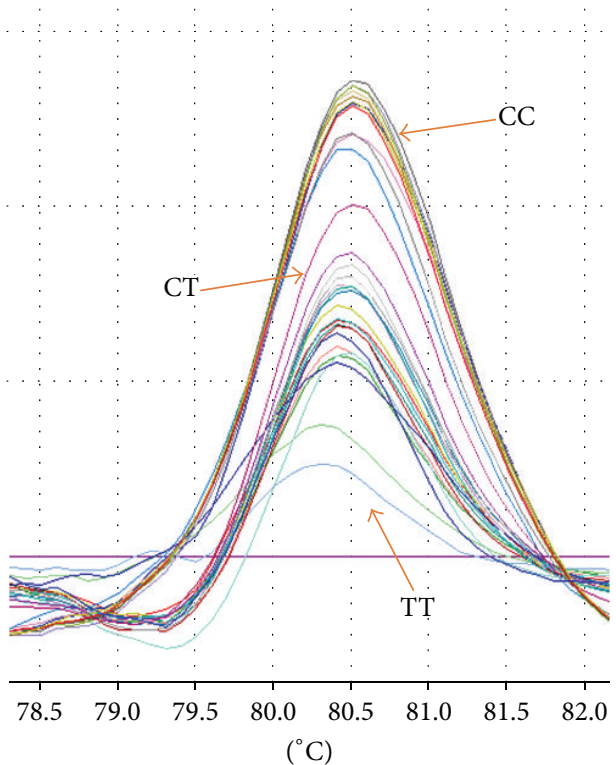

(b)

(a)

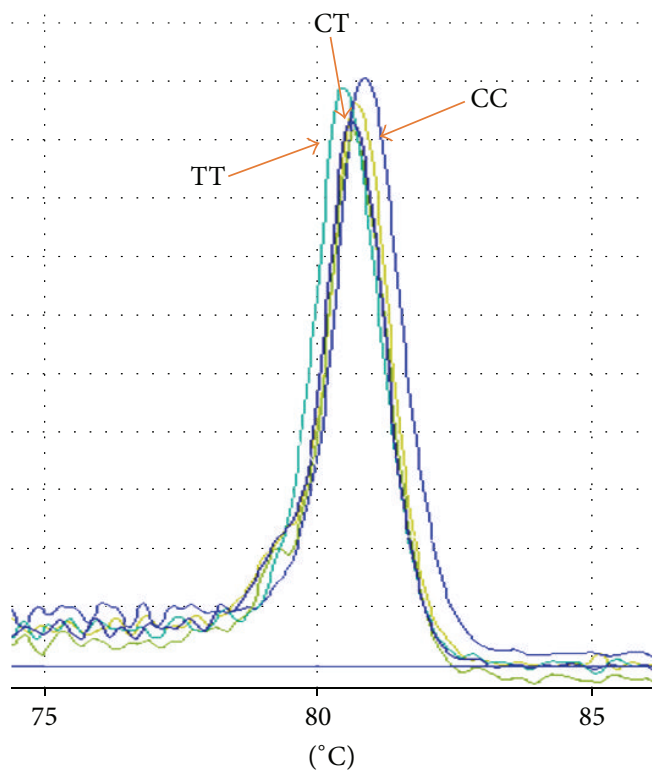

(c)

FIGURE 3: The difference graph of HRM analysis for the genotypes of R230C polymorphism. (a) demonstrated the normalized graph, (b) revealed the difference graph, and (c) was melting graph. In these graphs WT had higher Tm and HOM had lower Tm.

stored at $-20^{\circ} \mathrm{C}$ for further analysis. PCR optimization was done first for all primers, followed by DNA qualifications. The concentration of the extracted DNA was estimated using the NanoDrop in two OD wavelengths $260 \mathrm{~nm}$ and $280 \mathrm{~nm}$.

5.3. Genotyping of ABCA1 Gene Polymorphisms. Genotyping of these polymorphisms was done based on real time PCRHRM and the primers were designed and synthesized by NextGene. The PCR product of samples that were amplified from the respective genes was sequenced and confirmed the product. Those samples were used as a positive control for the respective genes. The negative control consisted of
PCR-grade water lacking the DNA template. All samples were genotyped by high resolution melting analysis by Rotor Gene 6000. PCR primers for R219K were forward primer CCATGTTGGAACGAAGTA and reverse primer GAAGTTTCTGAGCTTTGTG, for C69T were forward primer TCTCGCTCGCAATTACGG and reverse primer TGACCGATAGTAACCTCTGC, and for R230C were forward primer GATTGGCTTCAGGATGTCCATGTTG and reverse primer GTTTCTGAGCTTTGTGGCCT ACC. PCR was performed in a volume of $25 \mu \mathrm{L}$ consisting of about $1 \mu \mathrm{L}$ of genomic DNA, $0.5 \mu \mathrm{L}$ of each of the forward and reverse primers, $13 \mu \mathrm{L}$ of water, and $10 \mu \mathrm{L}$ Master Mix for 
HRM (EpiTect HRM Master Mix, QIGEN). The temperature was kept at 95 for $5 \mathrm{~min}$ for denaturation followed by 40 cycles of $20 \mathrm{~s}$ at $95^{\circ} \mathrm{C}, 10 \mathrm{~s}$ at $55^{\circ} \mathrm{C}$, and $20 \mathrm{~s}$ at $72^{\circ} \mathrm{C}$. The melting curves were normalized (temperature ranges on each side of the melting transition were chosen and the data points for a given sample were scaled between 0 and $100 \%$ fluorescent intensity). Used control samples (wild type (WT) and homozygous mutant (HOM)) were confirmed by sequencing. Table 1 demonstrated the sequence and length and $\mathrm{Tm}$ of each primer.

5.4. Statistical Analysis. The Statistical Package for Social Science (SPSS) (Version 21) was used to analyze the data in this study. Descriptive statistics were utilized to analyze all variable information such as demographics, anthropometric factors, and the genotypes of all the study subjects; moreover, all of these factors were compared by using Student's $t$-test; one-way ANOVA test was utilized to compare the group means and a level of $P<0.05$ was considered as statistically significant. Confidence intervals (95\%) were reported where appropriate. Allelic frequencies were calculated by the gene counting method and the genotype distribution was calculated with Hardy-Weinberg expectations by a chi-squared test.

$\begin{array}{ll}\text { Abbreviations } \\ \text { T2DM: } & \text { Type } 2 \text { diabetes mellitus } \\ \text { ABCA1: } & \text { ATP-binding cassette transporter A1 } \\ \text { WT: } & \text { Wild type } \\ \text { HET: } & \text { Heterozygous } \\ \text { HOM: } & \text { Homozygous } \\ \text { CI: } & \text { Confidence interval. }\end{array}$

\section{Conflict of Interests}

The authors declare that they have no conflict of interests regarding the publication of this paper.

\section{Authors' Contribution}

Patimah Ismail and Vasudevan Ramachandra contributed equally to this paper. Polin Haghvirdizadeh and Vasudevan Ramachandran conceived the study and Polin Haghvirdizadeh participated in the experimental design, data acquisition and analysis, and interpretation of results and drafted the paper. Polin Haghvirdizadeh, Vasudevan Ramachandran, Ali Etemad, Farzad Heidari, Nooshin Ghodsian, Norzian Bin Ismail, and Patimah Ismail interpreted the results and critically reviewed the study for important intellectual content. All authors approved the final version of the paper.

\section{Acknowledgment}

The authors would like to extend their gratitude to all the volunteers involved in this study.

\section{References}

[1] N. Unwin, D. Gan, and D. Whiting, "The IDF Diabetes Atlas: providing evidence, raising awareness and promoting action," Diabetes Research and Clinical Practice, vol. 87, no. 1, pp. 2-3, 2010.

[2] G. R. Letchuman, W. M. W. Nazaimoon, W. B. W. Mohamad et al., "Prevalence of diabetes in the Malaysian national health morbidity survey III 2006," The Medical Journal of Malaysia, vol. 65, no. 3, pp. 180-186, 2010.

[3] S.-S. Moon, J.-E. Lee, Y.-S. Lee et al., "Association of pyruvate dehydrogenase kinase 4 gene polymorphisms with type 2 diabetes and metabolic syndrome," Diabetes Research and Clinical Practice, vol. 95, no. 2, pp. 230-236, 2012.

[4] D. R. Whiting, L. Guariguata, C. Weil, and J. Shaw, "IDF diabetes atlas: global estimates of the prevalence of diabetes for 2011 and 2030," Diabetes Research and Clinical Practice, vol. 94, no. 3, pp. 311-321, 2011.

[5] M. M. Zaharna, A. A. Abed, and F. A. Sharif, "Calpain-10 gene polymorphism in type 2 diabetes mellitus patients in the gaza strip," Medical Principles and Practice, vol. 19, no. 6, pp. 457-462, 2010.

[6] N. Plengvidhya, "Molecular genetics of diabetes mellitus," Siriraj Medical Journal, vol. 60, no. 5, pp. 273-278, 2008.

[7] V. Kolovou, G. Kolovou, A. Marvaki et al., "ATP-binding cassette transporter A1 gene polymorphisms and serum lipid levels in young Greek nurses," Lipids in Health and Disease, vol. 10, article 56, 2011.

[8] H. A. Ergen, Ü. Zeybek, Ö. Gök, and Z. E. Karaali, "Investigation of $A B C A 1 \mathrm{C} 69 \mathrm{~T}$ polymorphism in patients with type 2 diabetes mellitus," Biochemia Medica, vol. 22, no. 1, pp. 114-120, 2012.

[9] Z. Guo, P. Wu, D. Xie et al., "A new discovered ABCAl gene polymorphisms and the association of ABCA1 SNPs with coronary artery disease and plasma lipids in Chinese population," Journal of Medical Colleges of PLA, vol. 26, no. 4, pp. 179-190, 2011.

[10] N. Çoban, A. Onat, E. Kömürcü-Bayrak, Ç. Güleç, G. Can, and N. Erginel-Ünaltuna, "Gender specific association of ABCA1 gene R219K variant in coronary disease risk through interactions with serum triglyceride elevation in Turkish adults," Anadolu Kardiyoloji Dergisi, vol. 14, no. 1, pp. 18-25, 2014.

[11] A. Ergen, S. Isbir, A. Tekeli, and T. Isbir, "Investigation of ABCA1 C69T and G-191C polymorphisms in coronary artery disease," In Vivo, vol. 22, no. 2, pp. 187-190, 2008.

[12] A. Cenarro, M. Artieda, S. Castillo et al., "A common variant in the ABCA1 gene is associated with a lower risk for premature coronary heart disease in familial hypercholesterolaemia," Journal of Medical Genetics, vol. 40, no. 3, pp. 163-168, 2003.

[13] K. K. Alharbi, I. A. Khan, N. M. Al-Daghri et al., "ABCA1 C69T gene polymorphism and risk of type 2 diabetes mellitus in a Saudi population," Journal of Biosciences, vol. 38, no. 5, pp. 893897,2013

[14] I. Porchay-Baldérelli, F. Péan, N. Emery et al., "Relationships between common polymorphisms of adenosine triphosphatebinding cassette transporter A1 and high-density lipoprotein cholesterol and coronary heart disease in a population with type 2 diabetes mellitus," Metabolism, vol. 58, no. 1, pp. 74-79, 2009.

[15] T. Villarreal-Molina, C. Posadas-Romero, S. Romero-Hidalgo et al., "The $A B C A 1$ Gene $\mathrm{R} 230 \mathrm{C}$ variant is associated with 
decreased risk of premature coronary artery disease: the Genetics of Atherosclerotic Disease (GEA) Study," PLoS ONE, vol. 7, no. 11, Article ID e49285, 2012.

[16] A. Kitjaroentham, H. Hananantachai, A. Tungtrongchitr, S. Pooudong, and R. Tungtrongchitr, "R219K polymorphism of ATP binding cassette transporter A1 related with low HDL in overweight/obese Thai males," Archives of Medical Research, vol. 38, no. 8, pp. 834-838, 2007.

[17] A. Pasdar, G. Yadegarfar, A. Cumming, L. Whalley, D. St. Clair, and M.-J. MacLeod, "The effect of ABCA1 gene polymorphisms on ischaemic stroke risk and relationship with lipid profile," BMC Medical Genetics, vol. 8, no. 1, article 30, 2007.

[18] J. L. Benton, J. Ding, M. Y. Tsai et al., "Associations between two common polymorphisms in the ABCAl gene and subclinical atherosclerosis: Multi-Ethnic Study of Atherosclerosis (MESA)," Atherosclerosis, vol. 193, no. 2, pp. 352-360, 2007.

[19] G. R. Letchuman, W. M. Wan Nazaimoon, W. B. Wan Mohamad et al., "Prevalence of diabetes in the Malaysian National Health Morbidity Survey III 2006," The Medical Journal of Malaysia, vol. 65, no. 3, pp. 180-186, 2010.

[20] O. Değer, Y. E. Yandi, M. Ayvaz, C. Erem, and A. B. Hacihasanoğlu, "Polymorphisms in ABC transporters (ABCA1 and ABCC8) in metabolic syndrome," Turkish Journal of Medical Sciences, vol. 43, no. 2, pp. 214-221, 2013. 


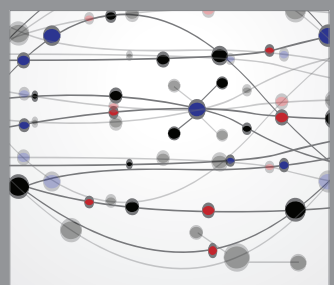

The Scientific World Journal
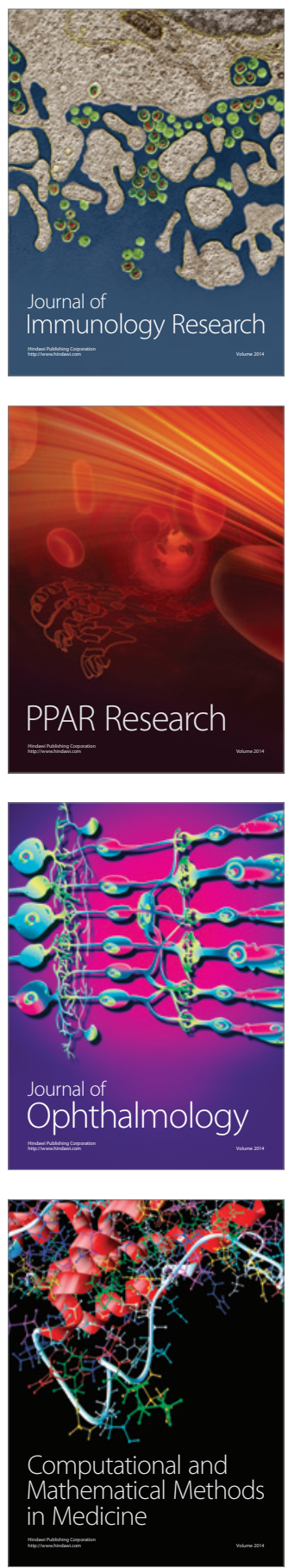

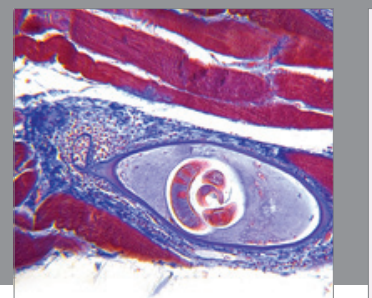

Gastroenterology

Research and Practice
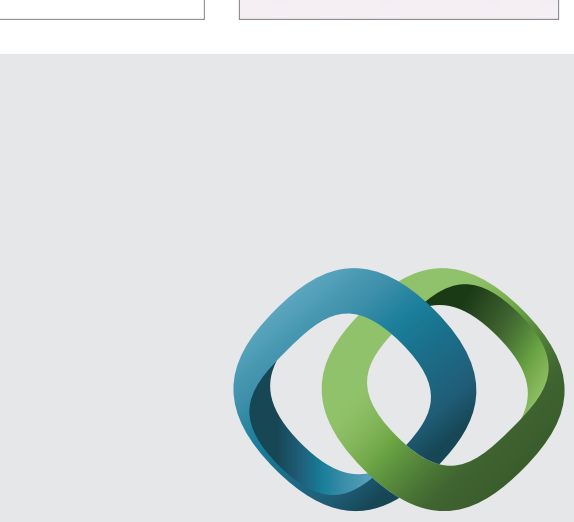

\section{Hindawi}

Submit your manuscripts at

http://www.hindawi.com
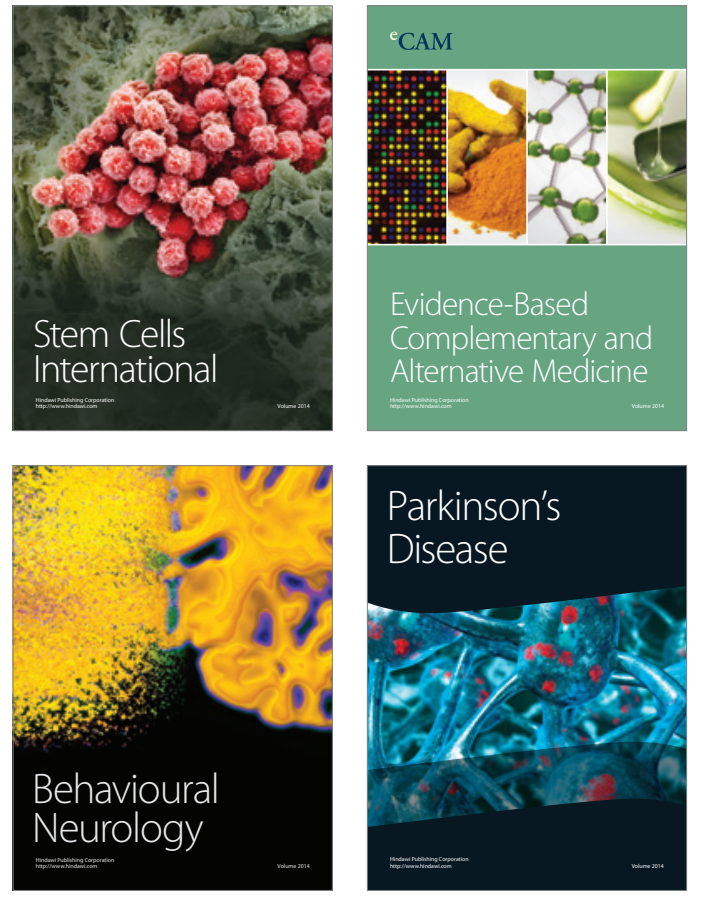
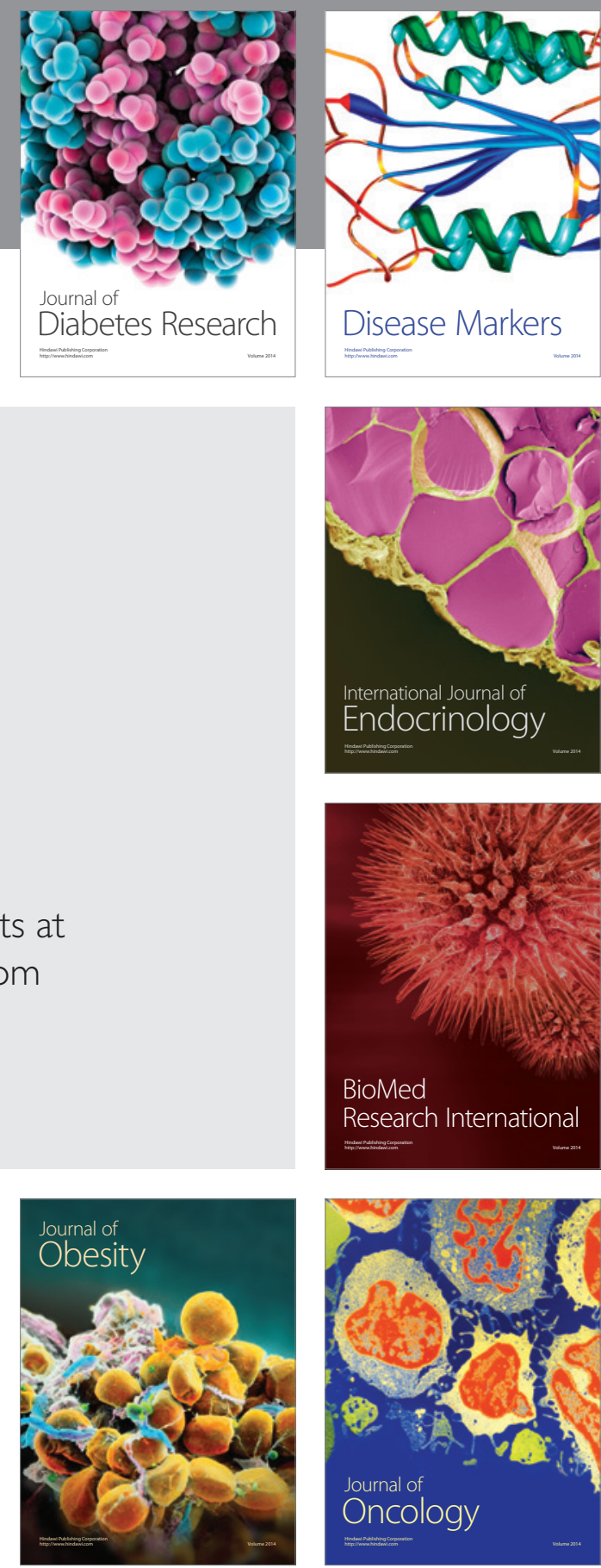

Disease Markers
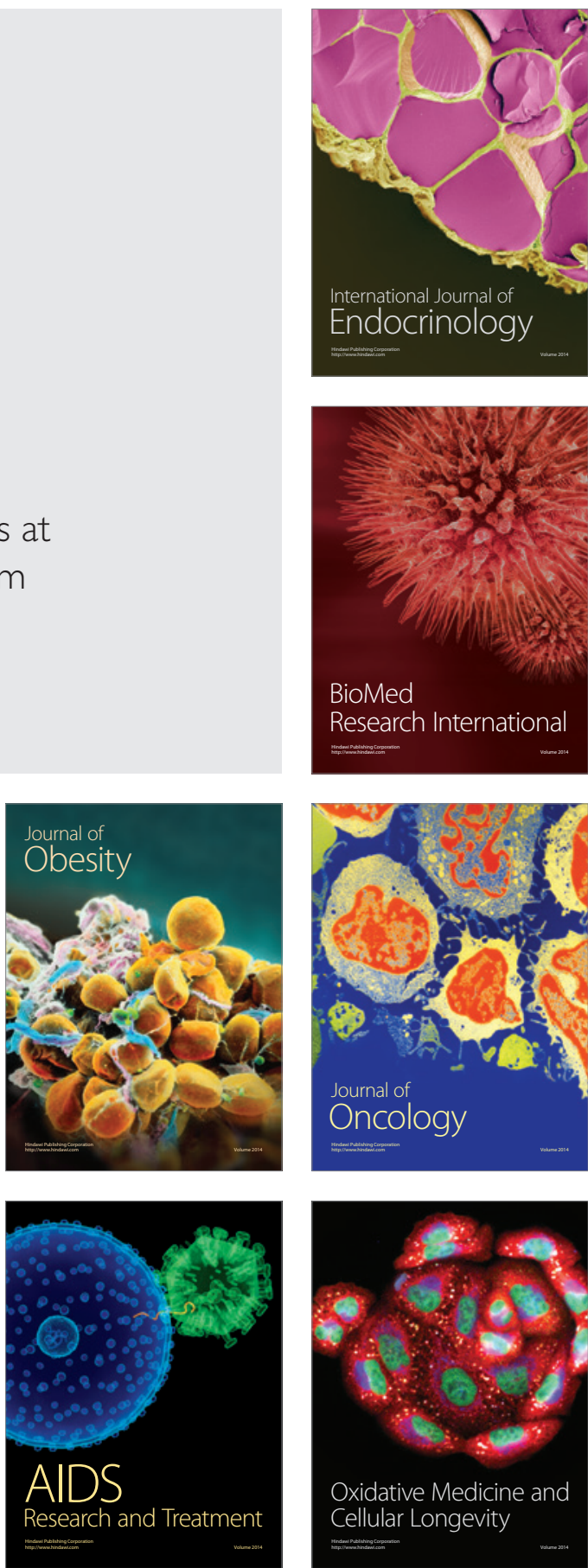